\title{
Discurso do Professor Octávio Bueno Magano
}

O prazer deste momento inunda a minha vida inteira.

A princípio, foi o incontido desejo de entrar para as Arcadas e o sentimento de que me habilitaria, assim, a participar de sua saga, entremada de glórias cívicas, da melopéia dos seus poetas e das sábias obras de seus juristas.

Quem poderia resistir, criado como eu na década de 30, ao impacto emocional deste estribilho: "Quando se sente bater no peito heróica pancada. " ou desta interrogação provocadora: "És Paulista? Ah ! então tu me compreendes !" Quem poderia deixar de se inflamar pela Academia, se era ela o centro de um dos mais gloriosos movimentos cívicos de nossa história, a Revolução Constitucionalista de 1932 ?

Menos imune não poderia ficar aos fascínios da Faculdade um adolescente que, embalado nos versos condoreiros de Castro Alves

$$
\begin{aligned}
& \text { "Quebre-se o cetro do Papa, } \\
& \text { Faça-se dele uma cruz, } \\
& \text { A púrpura sirva ao povo, } \\
& \text { Para cobrir os ombros nus" }
\end{aligned}
$$

e nos românticos de Âlvares de Azevedo

$$
\begin{aligned}
& \text { "Quando em meu peito rebentar-se a fibra, } \\
& \text { Que o espírito enlaça à dor vivente. " }
\end{aligned}
$$

via nela fervilhar ainda os debates em torno do repto dos modernistas de 22, propugnadores de uma poesia pura e desativada como esta de Mário de Andrade: "Brasil que eu sou porque é a minha expressão muito engraçada; Porque é o meu sentimento pachorrento; Porque é o meu jeito de ganhar dinheiro, de comer e de dormir".

Quanto à atração que, nessa quadra da vida, as obras dos juristas pudessem exercer sobre mim, devo confessar que não correspondia senão a um sentimento vago da sua importância para o meu futuro.

Tinha eu, como se vê, motivos de sobra para desejar incorporar-me à Faculdade, nunca tendo vacilado sobre ser isso exatamente o que queria. 
Depois, já com o penacho do XI de Agosto assaltou-me esta dúvida compartilhada certamente por muitos de meus colegas: deveríamos nós permitir que os estudos interferissem na nossa vida acadêmica?

Deixando a Faculdade em 1952, na verdade, nunca dela me apartei. Qual Pierrot, namorava-a de longe, acompanhando enternecido a sua excitante trajetória. Tirou-me desse torpor o Professor Sílvio Rodrigues, incentivando-me, com a mesma generosidade com que hoje me saudou, a subir passo a passo a escada estreita conducente ao ápice da carreira universitária.

Nesse difícil percurso, muitos foram os que me ajudaram. Se houvesse de os nomear a todos não desocuparia tão cedo esta tribuna. Quero, porém, na presente oportunidade, transmitir, a cada um deles, os meus agradecimentos mais sentidos.

$\mathrm{E}$, agora, aqui, como me desincumbir das delicadas funções inerentes ao meu cargo?

Deparo com a resposta no artigo 42 do antigo Regimento desta Faculdade onde se impõe ao Professor o dever de lecionar com eficiência as matérias componentes do programa de sua cadeira.

Mas o que significa lecionar com eficiência?

Significa, em primeiro lugar, ter presente que a docência constitui atividade voltada à busca da verdade. Mas não apenas da verdade inquestionável, que implica correspondência perfeita da idéia com a realidade; mas não exclusivamente da verdade demonstrável pelo silogismo. E sim, também, da verdade perquerida através da dialética, que parte de premissas problemáticas e conduz não à certeza mas à compreensão. Já se vê por aí que não falo da dialética como movimento histórico da realidade e sim da dialética entendida como lógica do diálogo. Refiro-me à atitude do espírito que procura conhecer a realidade por meio de aproximações progressivas feitas geralmente através do diálogo e que constitui, quiçá, o método mais próprio ao estudo das ciências humanas.

O professor, enquanto instrui, necessitando transmitir aos seus alunos um grande número de informações, pode e deve usar da retórica demonstrativa. Mas como lecionar não significa somente instruir senão também formar, quer dizer, incutir no espírito do estudante a necessidade de uma atitude crítica em face dos valores em que se funda a matéria versada não pode o professor prescindir do uso da dialética.

Reconheço que a utilização preponderante desse último método exigiria substanciais modificações nas condições de ensino vigorantes nesta Faculdade. Fora mister, pelo menos, que as disciplinas se multiplicassem, com a correspondente diminuição dos estudantes em cada uma delas e que o número de docentes habilitados igualmente se multiplicasse. Essas são, no entanto, modificações estruturais que 
talvez se retardem. Contudo, nem por isso serão menos esperadas. Como diria o poeta, "l'espoir ne fait pas de poussière."

Lecionar com eficiência significa, em segundo lugar, tratar os estudantes com amor e amizade, o que se faz necessário por serem eles e o professor parceiros indispensáveis de um mesmo processo. Importa, todavia, distinguir entre amizade autêntica, consolidada em virtude da busca de objetivos comuns, da amizade afetada, de caráter quase sempre demagógico.

Lecionar com eficiência significa, em terceiro lugar, ser perito na matéria em estudo, a fim de que possa o professor comunicar-se com os seus alunos de modo simples e claro. Ninguém realçou melhor tal exigência do que o Professor Emérito Luís Eulálio Bueno Vidigal, ao dar testemunho da sua longa experiência de docente: "Convenci-me, na prática do magistério, de que o professor deve ensinar pouco e bem."

Ser perito numa determinada matéria não quer dizer, com efeito, sabê-la em seus mínimos detalhes. Mas sim conhecê-la e interpretá-la à luz dos valores em que se funda e dos meios pelos quais possam ser estes realizados.

Essa última constatação leva-me à análise do Direito do Trabalho, cujos fundamentos consistem na proteção do trabalhador e na melhoria de sua condição social. Se sobre isso não discrepam os autores, larga se mostra a divergência doutrinária quanto aos caminhos a serem trilhados, na realização dos valores em causa.

Uma primeira corrente de juslaboralistas entende serem os mecanismos de tutela estatal os mais propícios para colimar os objetivos do Direito do Trabalho. Em posição diametralmente oposta, encontram-se os adeptos da idéia de que as forças do mercado, atuantes na sociedade capitalista, constituem os únicos fatores de efetiva proteção dos trabalhadores. A terceira escola é a dos que acreditam mais nos mecanismos da autotutela e da autocomposição.

A primeira corrente será talvez a de maior número de seguidores no Brasil, o que não é de estranhar levanđo-se em consideração haver o Direito do Trabalho nascido aqui sob o signo do paternalismo. Na sua versão mais ortodoxa, o escopo da questionada teoria era o de inserir os grupos profissionais e econômicos no seio do Estado para assim superarem-se as divergências entre ambos existentes. $\mathrm{Na}$ lógica do sistema, os sindicatos haviam de se converter em órgãos do Estado e, pois, em verdadeiras correias de transmissão entre os desígnios deste e o atuar das chamadas bases. As suas funções reivindicatórias tinham de ser sublimadas transformando-se em assistência social e recreativa, prodigalizada pelos seus departamentos médico, jurídico, odontológico e pelas suas colônias de férias. A greve e o "lock-out" se estigmatizavam como recursos anti-sociais. Para eliminar o risco de que pudessem ser desencadeados, criava-se a Justiça do Trabalho, dotada de poder normativo. 
Tal concepção implicando a existência de um sindicalismo atrelado ao Estado, mostra-se inteiramente incompativel com a abertura social e política urgentemente reclamada pela opinião pública.

A segunda corrente é a dos chamados neoliberais, liderada por Milton Friedman. O que, em suma, preconiza esse chefe de escola é a restauração do liberalismo desvinculado tanto quanto possivel de interferências estatais e isso sob o fundamento de que o Sindicato reduz o número de empregos e de que a única proteção segura e efícaz para a maioria dos trabalhadores é a proporcionada pela existência de numerosos empregadores.

Não há como concordar com as teses desse neoliberalismo por dois motivos principais: primeiro porque traz à tona uma sociedade atomizada composta de indivíduos, quando o fenômeno mais significativo da atualidade é o da propensão incoercivel à formação de grupos; segundo porque as condições sociais dos trabalhadores, no próprio país a que pertence Friedman, os Estados Unidos da América do Norte, só melhoraram substancialmente, a partir de 1935, com a edição do "Wagner Act", quando o sindicalismo se tornou atividade efetivamente protegida.

A terceira corrente é a dos autores para os quais a sociedade civil compõe-se de vários centros de interesses, os quais dão ensejo à formação de grupos, cuja autonomia não pode deixar de ser reconhecida. Esse é o modelo preconizado pela OIT, notadamente na Convenção $\mathrm{n}^{\circ}$ 87, de 1948. Por ele se pautam o sistema americano e o da Europa Ocidental. É, aliás, o único modelo conciliável com uma sociedade democrática, que para se qualificar como tal, há de ser livre e tolerar a formação de grupos, protegendo a respectiva autonomia.

A implantação, entre nós, desse último modelo exigirá radical transformação do direito coletivo do trabalho: em lugar do sindicato único, controlado pelo Estado, emergirá a pluralidade sindical; ao invés de condições de trabalho, originadas da lei, mais numerosas serão as derivadas de convenções coletivas. A garantia da autonomia sindical acarretará automaticamente a preponderância dos mecanismos de autocomposição, como os da negociação coletiva e os de arbitragem, sobre os processos coercitivos correspondentes à atuação do poder normativo da Justiça do Trabalho.

As indigitadas modificações do direito coletivo influirão, a seu turno, no direito individual, sendo de se esperar que a uniformidade de condições de trabalho, resultante do caráter genérico das leis, ceda o passo à diversificação provocada pela prática da convenção coletiva o que será, aliás, mais consetâneo com a heterogeneidade da realidade brasileira.

Feita, por essa maneira, a minha profissão de fé exsurge claro o entendimento de como pretendo me manter fiel ao juramento prestado perante o Diretor desta Faculdade, o Excelentíssimo Senhor 
Professor Vicente Marotta Rangel, no sentido de cumprir, com dedicação, os meus deveres de professor.

\section{Notas Bibliográficas}

O Professor Doutor Octávio Bueno Magano, filho de Virgílio dos Santos Magano e de Da. Beatriz Bueno Magano, nasceu em São Paulo, a 16 de janeiro de 1928. Casou-se com Da. Marlene Cabral Magano, sendo seus filhos Patrícia Cabral Magano (24-08-1954); Helena Cabral Magano (27-10-1956) e Márcio Cabral Magano (27-10-1957). Homem culto, tem bagagem invejável que, resumidamente, expomos a seguir:

\section{Diplomas e Títulos}

Professor Titular na Faculdade de Direito da Universidade de S. Paulo.

Presidente do Instituto Latino Americano de Derecho del Trabajo y de la Seguridad Social.

Master of Comparative Law - Universidade de Columbia de New York, Estados Unidos.

Comenda da Ordem do Mérito Judiciário do Trabalho, conferida pelo TST em junho de 1977.

Professor Honoris Causa da Faculdade de San Martin de Porres, em Lima.

Membro da Academia Ibero-Americana de Direito do Trabalho.

Professor Honorário da Faculdade de Direito de Marília.

Título de Notável Saber Jurídico que lhe foi conferido pela Universidade Federal do Paraná.

\section{Obras Publicadas}

Do Poder Diretivo na Empresa.

Organização Sindical Brasileira.

Manual de Direito do Trabalho - Parte Geral.

Manual de Direito do Trabalho - Vol. II.

Os Grupos de Empresas no Direito do Trabalho.

As Novas Tendências do Direito do Trabalho.

Lineamentos de Infortunística.

Lineamentos de Direito do Trabalho.

Introdução ao Direito Econômico. Além dos livros acima relacionados, publicou diversos artigos em revistas especializadas. 